\title{
Excavator hydraulic circuit solution to reduce dissipations and fuel consumption
}

\author{
Paolo Casoli ${ }^{1 *}$, Fabio Scolari ${ }^{1}$, Carlo Maria Vescovini $^{1}$, Davide Mesturini ${ }^{2}$, Filippo Zannoni ${ }^{2}$
}

1 Department of Engineering and Architecture, University of Parma, 43124 Parma, Italy. 2Walvoil S.p.A. - Via Adige 13/D, 42124 Reggio Emilia (Italy)

\begin{abstract}
In the field of mobile machine the research is mainly focused on solutions to reduce the energy dissipations and fuel consumptions being these machines mainly equipped with Diesel engines. This paper presents a solution for improving the performance of a traditional Load sensing flow sharing circuit. The solution concerns the insertion of a Load sensing signal conditioner (LSc), developed by Walvoil S.p.A., that permits to dynamically change the pressure drop across the directional valves. A careful control of this new component permits to obtain a reduction of the fuel consumption without changing the performance of the machine taking as reference a JCMAS duty cycle. This paper presents the mathematical model of a 9 ton excavator that was previously validated with tests carried out on both the single hydraulic and the excavator main components like pump and flow sharing valves. The LSc model was developed and added to the traditional hydraulic circuit. The model of the excavator hydraulic circuit with this new component has permitted to simulate the energy saving achievable in comparison with the traditional solution. The paper presents the relevance of a carefully control of this new device in order to maximize the performance. The physical prototyping of this device has been already developed and will be installed in a mobile machine to confirm the simulated performance.
\end{abstract}

\section{Introduction}

In the field of mobile machine emissions limits for the prime mover have brought the researchers to investigated new solutions to reduce the energy dissipations and fuel consumptions.

Concerning the excavators in $[1,2]$ new systems solutions are proposed mainly focused on layouts optimization and solutions for energy recovery. Energy recovery could be realized starting from kinetic or potential energy from boom and swing movements [3-5]. Other aspects concern the optimization of power transmission [6-8] without neglecting the importance of the optimal match between the hydraulic system and the thermal engine [9]. Mathematical models are necessaries for evaluating different solutions, the models could be based on lumped parameters approach for the systems simulation [10-15] while when a component needs to be optimized dedicated detailed models should be developed; the literature reports research activities carried out on gear pumps [16-21]; fixed displacement gerotor pump are investigated in [22-27]. Particular applications like lubrication pump are investigated in [28-30]; topics concerning the condition monitoring applied to hydraulic pumps are reported in [31,32]; other papers are focused on detailed analysis of hydraulic valves [33-35]. Focused on excavator hydraulic solutions in [36] is presented a system with two pumps that permits to feed users with similar load reducing the compensator losses. Independent metering solutions have been investigated in [37], while the displacement control solution where each actuator is fed by a dedicated pump is presented in [38].

Hybridization and energy recovery systems are promising solutions as reported in [39-42]. The optimal utilization of the stored energy required dedicated control strategy that can be obtained with digital programming algorithm [43].

A relevant branch of research involves the replacing of traditional valves with pump controlled cylinder as reported in [44-46]. Different configurations can be adopted and optimized, in [47, 48] the authors propose

\footnotetext{
*Corresponding author: paolo.casoli@unipr.it
} 
different architectures for pump controlled hydraulic cylinder. A review of solutions based on fixed or variable displacement pumps are in [49] while a solution with fixed pump and variable-speed electric drives is investigated in $[10]$.

The solution proposed in this paper is based on a device to be added to the existing circuit, this device permits to change the LS signal toward the pump regulator changing the pressure drop across the directional valves, it is an easier solution that can anyway contribute to reduce the energy dissipation.

The mathematical model of this device [13] has been added to the already developed mathematical model of a standard excavator. The mathematical model of the excavator was developed and validated as reported in [5054]. The model is based on a lumped parameter approach and include the models of pump, directional flow control valves, hydraulic lines, kinematics of the front equipment. The model was validated with data from experimental activities carried out on both pumps and valves at the test bench and on the excavator [55, 56]. The excavator model was modified with the addition of the model of the LS conditioner and used to simulate the energy saving achievable on a defined duty cycle [57].

The control strategy of the LSc, based on the user needs, was developed in Matlab $^{\odot}$ environment, therefore a co-simulation was carried out linking the model developed in Amesim ${ }^{\odot}$ with the code developed in Matlab $^{\odot}$.

This paper is organized as follows: in Section 2 the LS signal conditioner is described; in section 3 the whole hydraulic circuit of the excavator with LSc installed is presented; in section 4 the control strategy is presented; finally, the results in terms of energy saving and users controllability are reported in section 5.

\section{Load Sensing signal conditioner (LSc)}

A Load Sensing signal conditioner has been developed by Walvoil S.p.A with the aim of being easily installed in machine with LS post-compensated circuit. In Fig. 1 the ISO scheme of the conditioner is reported.

The LSc is installed along the LS line and can change the signal from the load respect to the signal transmitted to the pump's regulator. The conditioner can anyway leave the signal unchanged, but has been conceived to increase or reduce the original LS signal. On one hand a reduction of the LS signal determines a reduction of the pressure drop through the metering valves, the valves could anyway be more open and the flow rate remain unchanged, with a reduction of the flow losses; on the other hand an increment of the LS signal transmitted to the regulator of the pump increases the pressure drop through the metering, the flow losses increase but a more reactive command could be obtained.

With reference to the ISO scheme, Fig. 1, the core of the LSc is the main stage that is actuated by the pilot pressure controlled by the pilot stage. Three working conditions are possible:

1. LS unchanged (copier): the pilot stage keeps a pressure on area A2 able to balance the force of the spring in A3;

2. LS increase: increasing the pressure Pil the balance of the main stage is obtained when the LSc is higher of the LS.

3. LS decrease: reducing the pressure Pil the balance of the main stage is reached with a LSc pressure lower then LS pressure.

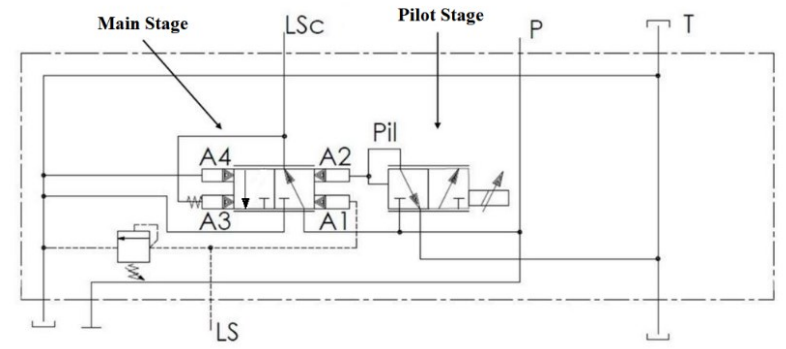

Fig. 1. ISO scheme of the load sensing conditioner

The LSc can be easily actuated with an electrical signal and it can span from each working condition very quickly, therefore a customized actuation of this device permit to maximize the performance of the implements connected to the hydraulic circuit from the point of view of the energy saving but also for improving the response of the actuators to the user command. 


\section{Excavator hydraulic circuit with LSc}

In fig. 2 the e ISO scheme of the excavator with installed the conditioner is presented.

The hydraulic excavator is equipped with $46 \mathrm{~kW}$ Diesel engine, the hydraulic circuit is a Load sensing system with a flow sharing directional valve and a variable displacement axial piston pump.

The LSc is installed along the LS line from the highest load to the regulator of the pump. From the ISO scheme is clear that the hydraulic circuit of the excavator remains exactly equal to the original, therefore this solution could be easily applied to existing machines.

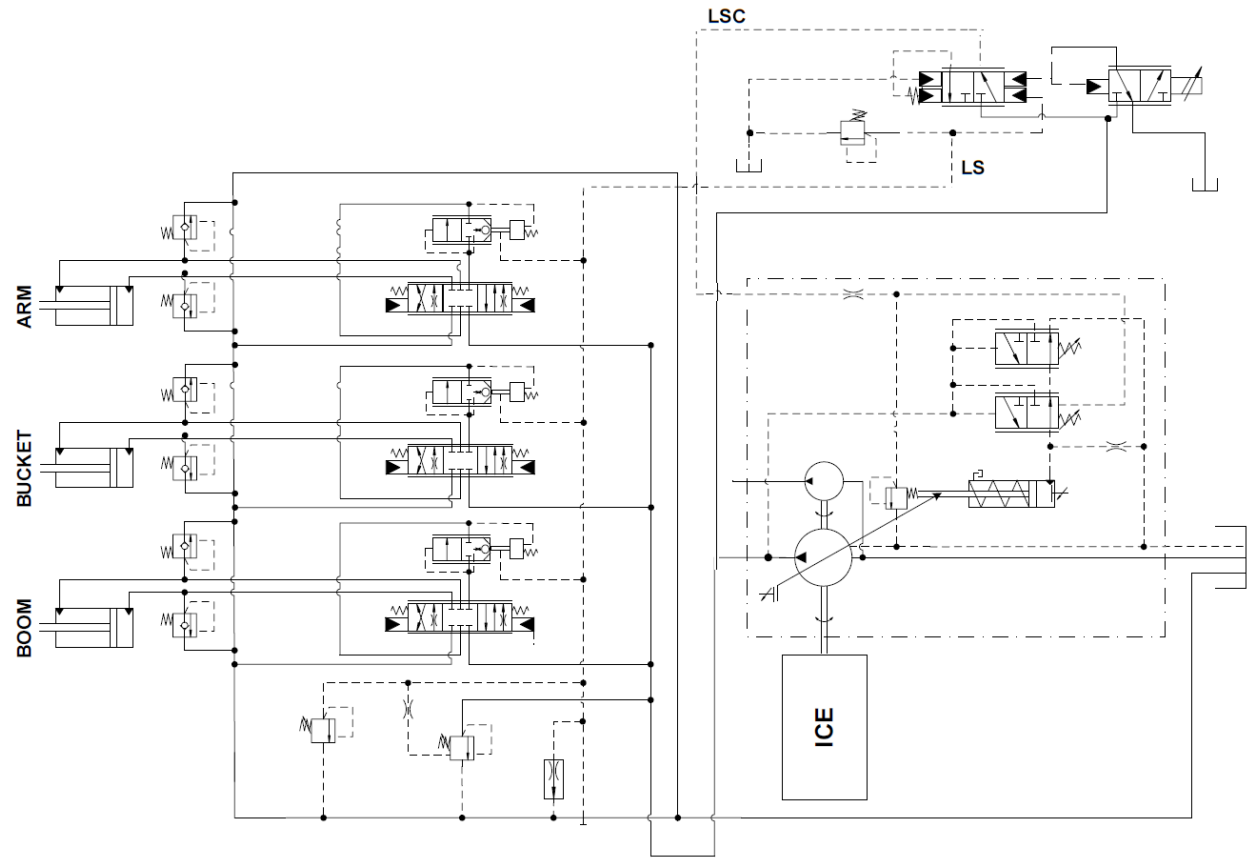

Fig. 2. ISO scheme of the modified hydraulic circuit of the excavator

\section{LS conditioner control strategy}

Once the load sensing conditioner has been inserted into the circuit a control system of the solenoid valve of the pilot stage must be implemented. The target is to maximize the performance, then step by step during the simulated duty cycle the correct control of the LSc permits to have an optimized load sensing signal modification.

The best strategy is to control the load sensing conditioner on the basis of the position of the spool of the directional valves. When the target is to reduce the energy losses the LSc must reduce the LS signal, but when directional valve is working close to its maximum opening a reduction of the pressure drop leads to a reduction of the flow rate. Then the LSc can interview only for suitable openings of the distributors, while the LS signal is kept unchanged when one of the valves is close to its maximum opening. This issue is not relevant when the target is to increase the LS because the operator requires a higher speeds of the users, but this working conditions is not presented in this paper.

In more detail is relevant to know the spool position of the valve, although not the most loaded, that has the spool close to its maximum opening. In this research has been assumed that if there is a valve close to the maximum opening the intervention of the LSc, toward a decrement of the LS signal, must be gradually deactivated, to avoid a flow rate reduction and a decrease of the user speed movement; details are reported in section 6. The model of the control algorithm was developed in Simulink ${ }^{\circledR}$ and implemented in Amesim ${ }^{\circledR}$ environment.

Figure 3 reports the Amesim sketch model of the LSc control, the input signals coming from the load pressure transducers and spool position sensors related to each user; these signals enter in the Simulink ${ }^{\circledR}$ sub-model, which 
processes them providing an output value between zero and one, this output is then transformed in current that will excite the pilot stage of the LSc.

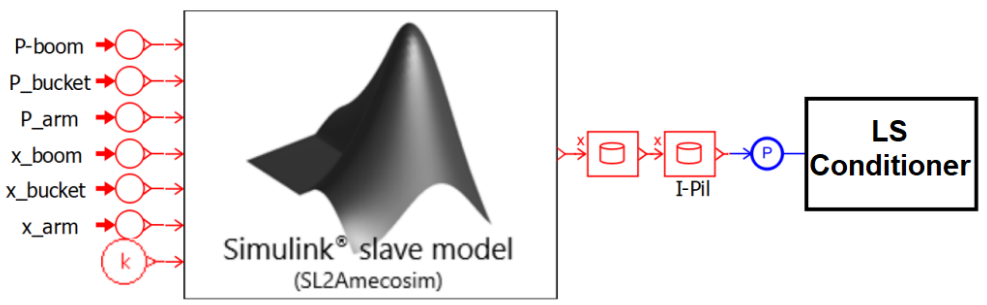

Fig. 3. Amesim model of the LSc control

\section{Results}

When the target is to obtain an energy savings it is necessary to condition the load sensing signal in such a way to make it lower than the real one. Many configurations of the LSc can be investigated changing the geometrical features of the LSc main stage, in particular the pilot area A1-4 and the spring stiffness affects the working conditions of the LSc. In this paper, for reason of brevity, are reported only configurations that differ from each other for the spring stiffness (in A3, Fig. 1).

In order to work as a copier the pilot stage must supply a pressure able to balance the spring on A3; therefore, the level of the current to supply to the pilot stage is correlated to the stiffness of the spring. Three different values of the spring stiffness have been considered (not reported for confidential reasons) and identified with letters A, $\mathrm{B}, \mathrm{C}$. Spring $\mathrm{C}$ is the one with the highest stiffness.

When the pilot stage is not activated the LS signal is reduced of different values that are equal to -4 bar when spring $A$ is installed, -8 bar with spring B and -9 bar with spring $C$. The pump margin never changes because the regulator of the pump has not been modified, but the pressure drop through the metering valve are reduced of the same values. For all the springs considered two control maps have been implemented. The conditions identified with Map 1 considers a reduction of the LS signal till the spool is open less than $60 \%$ of the total opening, from $60 \%$ to $90 \%$ the current is supplied to the pilot stage till the LSc starts to work as a copier. With the condition identified as Map 2 the reduction of the LS signal remains as long as the spool is below $80 \%$ of its maximum opening, then the electrical signal is gradually supplied to the solenoid till the LSc starts to work as a copier. Figure 4 reports the stroke-current map for the case A. The whole analysis refers to a simulation of a digging cycle, the model simulates the movements of the front equipment without soil interaction, following a duty cycle (DC) defined by JCMAS standard [57].

Figure 5-7 report a comparison between the movements of the users (boom, arm and bucket) respect to a reference duty cycle for the new configuration with spring A; the courses of the original version of the hydraulic circuit is reported with label STD.

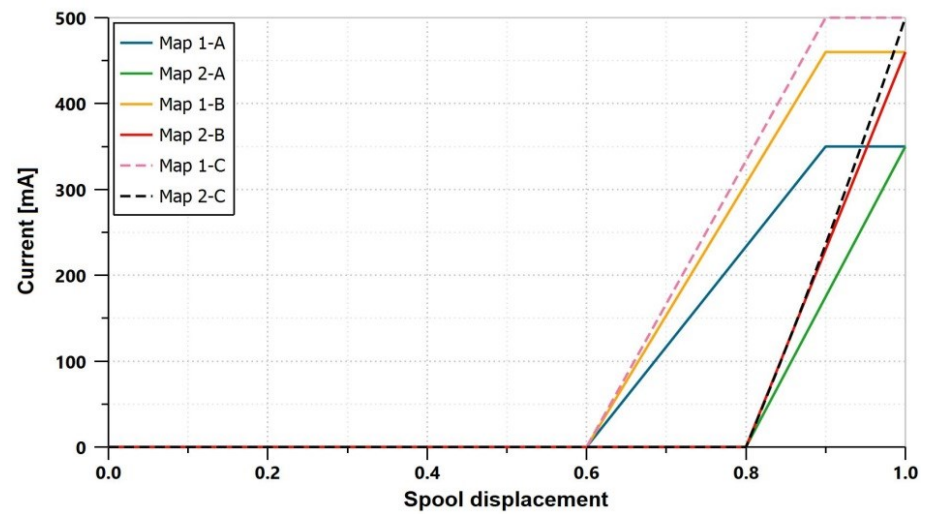

Fig. 4. Stroke-current maps of the LSc controller 


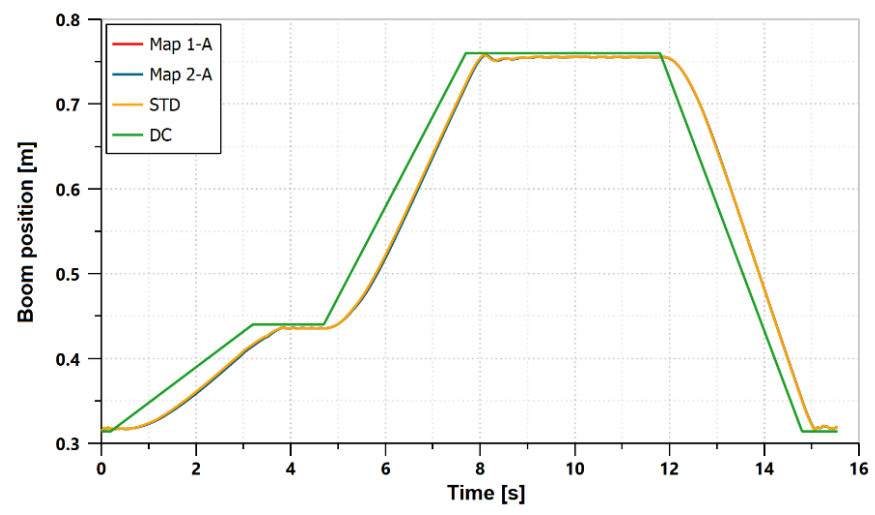

Fig. 5. Boom duty cycle, reference (DC) and simulations - case A

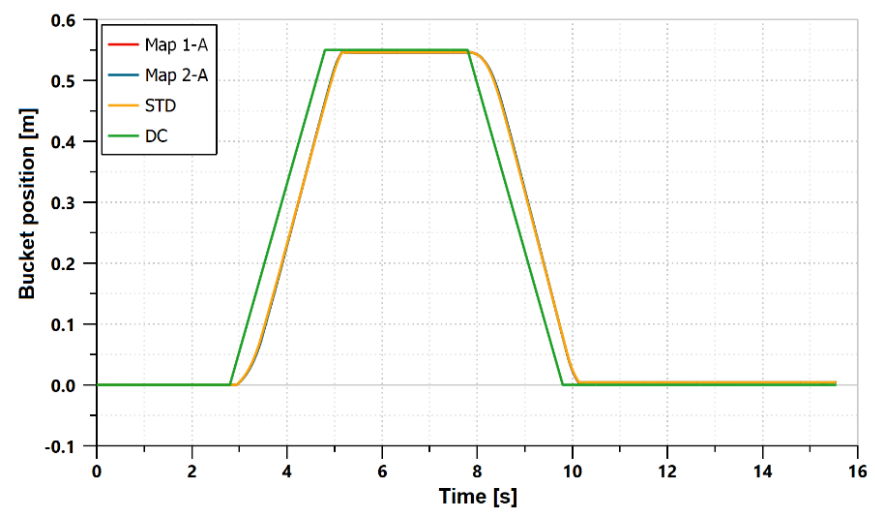

Fig. 6. Bucket duty cycle, reference (DC) and simulations - case A

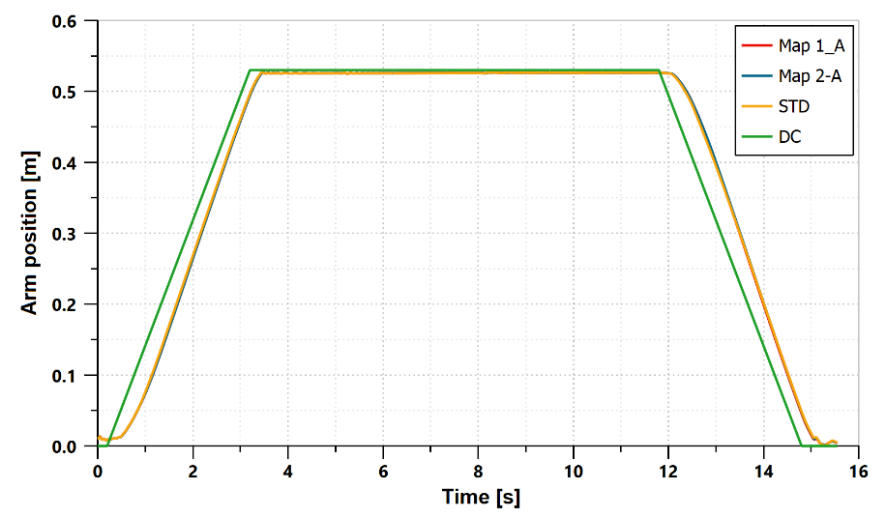

Fig. 7. Arm duty cycle, reference (DC) and simulations - case A 


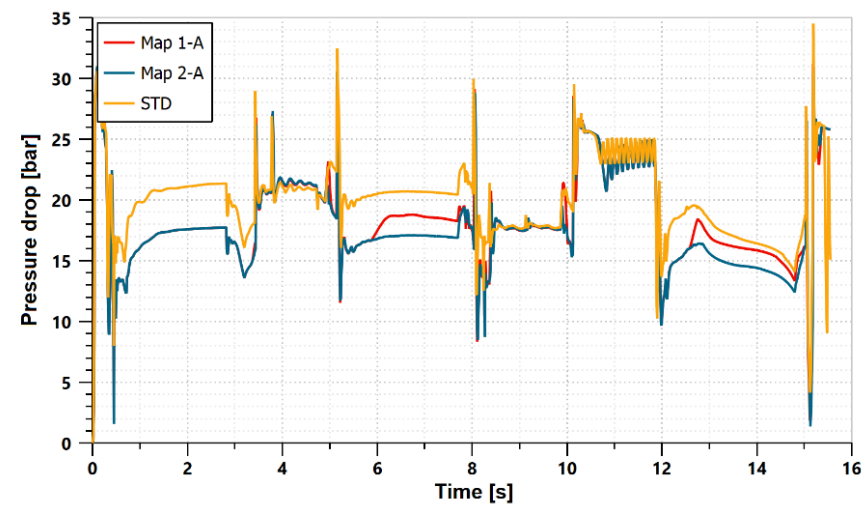

Fig. 8. Pressure drop through the metering valves vs Time - case A

In fig. 8 the courses of the pressure drop through the metering valves are reported; it is the same as that of the standard configuration (STD) as long as the LSc works as a copier, while it decreases following the reduction of the LS signal. The pressure drop of the standard configuration is equal to the pump margin.

In both the two configurations the conditioning of the LS signal does not involve controllability problems: as a matter of fact the duty cycle (DC) is respected for all the three actuators as shown in Figures 5-7, all the actuators follow the work cycle, overlapping the trends obtained with the STD circuit.

Using the spring with stiffness identified with letter B, that is higher respect stiffness A, the LS reduction reaches the value of -8bar. To set the working conditions as copier the current must be higher and equal to 460 mA. Again, two control maps have been considered with a control strategy equal to the previous case, fig. 4 .

A stronger reduction of the pressure drop is clearly visible in fig.9.

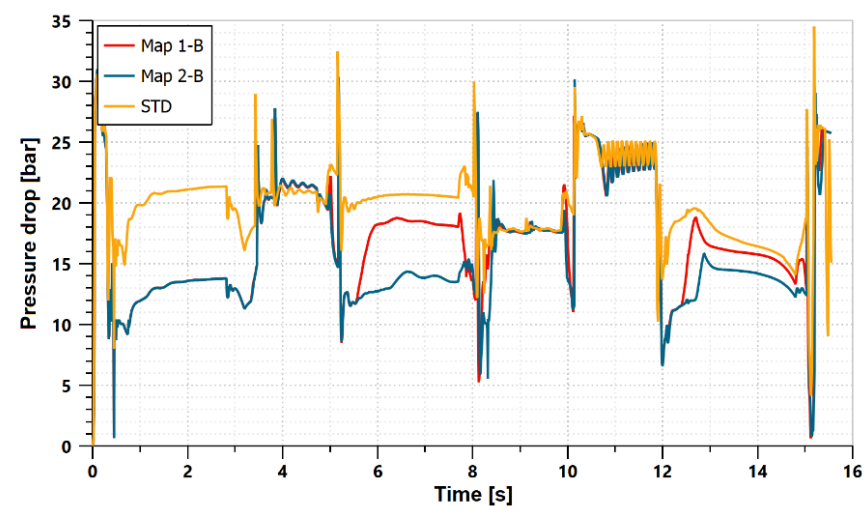

Fig. 9. Pressure drop through the metering valves vs Time- case B

The last configuration, spring stiffness $\mathrm{C}$, presents a pressure drop through the metering valves reduction of -9 bar, therefore a higher current is necessary to work as a copier $(500 \mathrm{~mA})$. The pressure drop reduction during the duty cycle is reported in fig. 10 . 


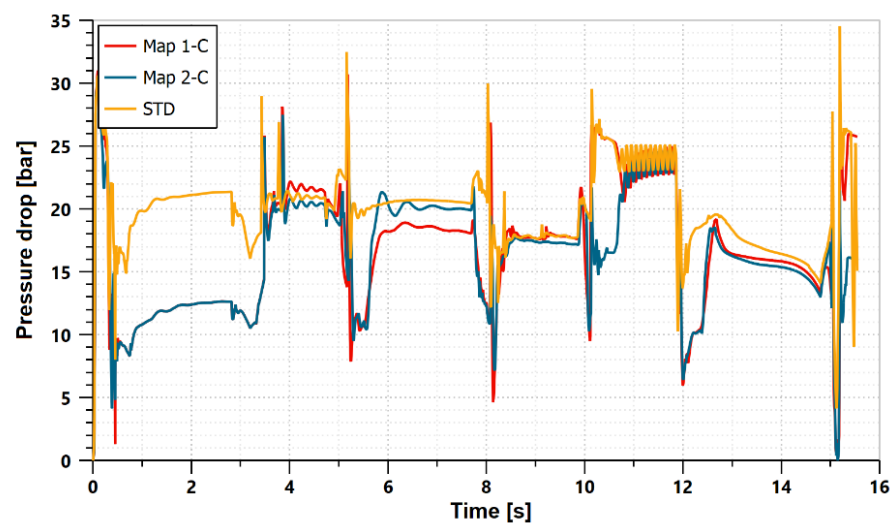

Fig. 10 Pressure drop through the metering valves vs Time- case C

For brevity the results of the movements of the users about the cases with spring B and C are not reported, the results are about the same as those found with case A; however Table 2 reports the position errors for all the cases.

\subsection{Performance analysis}

The main target is to reduce the energy dissipation and fuel consumption, for each configuration these values have been calculated and reported in table 1.

Table 1 reports the relative percentage compared to the consumption values obtained with the standard circuit. The table reports the fuel consumptions that is a parameter affected by the engine maps adopted and the mechanical energy absorbed by the pump shaft. A saving of the mechanical energy and of the fuel consumption is evident. The best results are found when the pressure drop reduction is the highest (case C) and when LSc works till the $80 \%$ of the spool maximum opening. The configuration 6 of table 2 represents the maximum saving obtainable, a further reduction of the pressure drop or an extension of the range of activation of the LSc (more than $80 \%$ of the spool maximum opening) makes impossible to respect the reference duty cycle.

Table 1. Energy savings

\begin{tabular}{|c|c|c|c|}
\hline Configuration & Spring & $\begin{array}{c}\text { Mechanical Energy } \\
\text { saving [\%] }\end{array}$ & $\begin{array}{c}\text { Fuel saving } \\
{[\%]}\end{array}$ \\
\hline STD & 1 & 1 & 1 \\
\hline 1 & \multirow{2}{*}{ A } & 1.55 & 0.74 \\
\hline 2 & & 2.82 & 1.32 \\
\hline 3 & \multirow{2}{*}{ B } & 3.85 & 1.78 \\
\hline 4 & & 6.29 & 2.88 \\
\hline 5 & \multirow{2}{*}{$\mathrm{C}$} & 4.28 & 1.98 \\
\hline 6 & & 6.96 & 3.18 \\
\hline
\end{tabular}

To verify the performance of the LSc from the point view of the operations of the excavator front equipment the instantaneous position of each users has been compared with a reference value that is the duty cycle DC.

Eq. (1) quantifies the mean square error considering the real position $\mathrm{y}_{\mathrm{r}}$ and the theoretical position $\mathrm{y}_{\mathrm{t}}$ :

$$
R M S E=\sqrt{\frac{\sum_{i=1}^{N}\left(y_{r, i}-y_{t, i}\right)^{2}}{N}}
$$

Moreover, to make the values for each user comparable, the RMSE are normalized with respect to the maximum stroke of each actuator (NRMSE): 


$$
N R M S E=\sqrt{\frac{\sum_{i=1}^{N}\left(y_{r, i}-y_{t, i}\right)^{2}}{N}} \cdot \frac{1}{y_{t, \max }-y_{t, \min }}
$$

Table 2. Position error of the front equipment

\begin{tabular}{|c|c|c|c|c|}
\hline \multirow[t]{2}{*}{ Configuration } & \multirow[t]{2}{*}{ Spring } & \multicolumn{3}{|c|}{$\begin{array}{c}\text { NRMSE } \\
{[\%]}\end{array}$} \\
\hline & & Boom & Bucket & Arm \\
\hline Duty Cycle & \multirow{2}{*}{ / } & 1 & 1 & 1 \\
\hline STD & & 7.37 & 8.41 & 6.70 \\
\hline 1 & \multirow{2}{*}{ A } & 7.55 & 8.54 & 6.90 \\
\hline 2 & & 7.64 & 8.56 & 7.01 \\
\hline 3 & \multirow{2}{*}{ B } & 7.70 & 8.92 & 7.25 \\
\hline 4 & & 8.01 & 9.15 & 7.43 \\
\hline 5 & \multirow{2}{*}{$\mathrm{C}$} & 7.75 & 9.06 & 7.38 \\
\hline 6 & & 8.09 & 9.32 & 7.57 \\
\hline
\end{tabular}

Table 2 shows the NRMSE values for each configuration and each actuator. It is important to point out that also the standard cycle differs from the duty cycle trend, taking the values of the standard cycle as a reference the deviations from this value are very small, therefore the proposed solution does not present a drop of performance in terms of operability of the excavator front equipment.

\section{Conclusion}

In this paper a solution to reduce the energy dissipation in a standard Load Sensing flow sharing hydraulic circuit has been presented. A device (LSc) acts to change the LS signal toward the pump's regulator with the main target of reducing the pressure drop through the metering valves and the corresponding losses. The device can keep the LS signal unchanged when the operative working conditions of one of the valves is close to its maximum opening, while it can reduce the LS signal and, as a consequence, the pressure drop through all the valves, when the valves are enough far from their maximum opening, to keep unchanged the flow rate to the actuators. The device could also increase the LS signal to increase the pressure drop through the metering valves when an increase of the speed operations is required.

The developed model has permitted to quantify the energy saving reachable with this solution and with different values of pressure drop reduction and different LSc control maps.

The results concern also the verification of the operability of the excavator front equipment, the reference duty cycle has been always respected.

The described device can be easily added in already existing hydraulic circuits based on LS flow sharing concept, moreover the low cost of the intervention makes this solution affordable for reducing the fuel consumption of mobile machines with LS post-compensated circuit.

\section{References}

1. M. Vukovic, R. Leifeld, H. Murrenhoff, Reducing Fuel Consumption in Hydraulic Excavators-A Comprehensive Analysis. 2017 Energies 10.5, p. 687. doi: 10.3390/en10050687.

2. M. Inderelst, F.D. Weidner, C. Stammen, Quantification of Energy Saving Influencers. 21t Excavator Hydraulic System - A Holistic Investigation? 2018, 11th International Fluid Power Conference 19th - 21th March

3. Joo, C., Stangl, M. Application of Power Regenerative Boom system to excavator. 2016 In Proceedings of the 10. IFK: International Fluid Power Conference, Dresden, Germany, 8-10 March; Volume 3, pp. 175-184;

4. Li, J.; Zhao, J.; Zhang, X. A Novel Energy Recovery System Integrating Flywheel and Flow Regeneration for a Hydraulic Excavator Boom System. Energies 2020,13, 315. DOI: 10.3390/en13020315.

5. Guan, C. \& Xu, X. \& Lin, X. \& Wang, S.-H. Recovering system of swing braking energy in hydraulic excavator. Zhejiang Daxue Xuebao (Gongxue Ban)/Journal of Zhejiang University (Engineering Science) 2012. 46. 142-149. DOI: 10.3785/j.issn.1008-973X.2012.01.23. 
6. Rossetti A., and Macor A., ulti-objective optimization of hydro-mechanical power split transmissions. Mechanism and Machine Theory 2013, 62(4), 112-128. DOI:10.1016/j.mechmachtheory.2012.11.009.

7. Rossetti A., Macor A., Benato A. "Impact of control strategies on the emissions in a city bus equipped with power-split transmission" Transportation Research Part D: Transport and Environment, Volume 50, 1 January 2017, Pages 357-371. DOI: 10.1016/j.trd.2016.11.025. Codice Scopus: 2-s2.0-85000426786.

8. Rossetti A., Macor A., Scamperle M. "Optimization of components and layouts of hydromechanical transmissions"International Journal of Fluid Power 2017,Volume 18, Issue 2, 4 May, Pages 123-134. DOI: 10.1080/14399776.2017.1296746.

9. Casoli P., Gambarotta A., Pompini N., Riccò L.; Coupling excavator hydraulic system and internal combustion engine models for the real-time simulation; Control Engineering Practice, 2015, pp. 2637 http://dx.doi.org/10.1016/j.conengprac.2015.04.003.

10. Casoli, P., Scolari, F., Minav, T., Rundo, M. Comparative energy analysis of a load sensing system and a zonal hydraulics for a 9-tonne excavator, Actuators 2020, 9(2):39 . DOI: 10.3390/ACT9020039

11. Pintore F., Borghi M., Morselli R., Benevelli A., Zardin B., Belluzzi F. Modelling and Simulation of the Hydraulic Circuit of an Agricultural Tractor. ASME. Fluid Power Systems Technology 2014, 8th FPNI Ph.D Symposium on Fluid Power:V001T04A004. doi:10.1115/FPNI2014-7848.

12. Andrea Gaiola, Barbara Zardin, Paolo Casoli, Massimo Borghi, Francesca Mazzali, Francesco Pintore, Stefano Fiorati, The Hydraulic Power Generation and Transmission on Agricultural Tractors: feasible architectures to reduce dissipation and fuel consumption - Part I. E3S Web of Conferences 197, 07009, 2020 75th National ATI Congress - \#7 Clean Energy for all (ATI 2020) . DOI:10.1051/e3sconf/202019707009

13. Paolo Casoli, Barbara Zardin, Salvatore Ardizio, Massimo Borghi, Francesco Pintore, Davide Mesturini, The Hydraulic Power Generation and Transmission on Agricultural Tractors: feasible architectures to reduce dissipation and fuel consumption - Part 2, E3S Web Conf. 19707010 (2020), DOI: 10.1051/e3sconf/202019707010

14. Zardin, B.; Cillo, G.; Rinaldini, C.A.; Mattarelli, E.; Borghi, M. Pressure Losses in Hydraulic Manifolds. Energies 2017, 10, 310.

15. Zardin, B.; Cillo, G.; Borghi, M.; D'Adamo, A.; Fontanesi, S. Pressure Losses in Multiple-Elbow Paths and in V-Bends of Hydraulic Manifolds. Energies 2017, 10, 788.

16. Rundo M. Models for Flow Rate Simulation in Gear Pumps: A Review, Energies 2017 10(9), 1261, 2017; DOI:10.3390/en10091261.

17. E. Frosina, A. Senatore, M. Rigosi. Study of a High-Pressure External Gear Pump with a Computational Fluid Dynamic Modeling Approach. Energies 2017, 10(8), pp. 1113 - 1133

18. Corvaglia, A., Rundo, M., Casoli, P., Lettini, A., Evaluation of Tooth Space Pressure and Incomplete Filling in External Gear Pumps by Means of Three-Dimensional CFD Simulations. Energies 2021, 14, 342. https://doi.org/10.3390/en14020342

19. Zardin, B.; Natali, E.; Borghi, M. Evaluation of the Hydro-Mechanical Efficiency of External Gear Pumps. Energies 2019, 12, 2468. DOI:10.3390/en12132468.

20. Casoli, P., Scolari, F., Rundo M., Lettini, A., Rigosi M. CFD Analyses of Textured Surfaces for Tribological Improvements in Hydraulic Pumps. Energies 2020, 13, 5799. https://doi.org/10.3390/en13215799

21. Zardin, B.; Natali, E.; Borghi, M. Evaluation of the Hydro-Mechanical Efficiency of External Gear Pumps. Energies 2019, 12, 2468. https://doi.org/10.3390/en12132468

22. Altare G., Rundo M. CFD Analysis of gerotor lubricating pumps at high speed: geometric features influencing the filling capability. Proceedings of the ASME/BATH 2015 Symposium on Fluid Power and Motion Control (FPMC), Oct. 12-14, 2015, Chicago, IL, USA. Paper no. FPMC2015-9539. DOI: 10.1115/FPMC2015-9539.

23. Siano, D., Frosina, E., Senatore, A., " Diagnostic Process by Using Vibrational Sensors for Monitoring Cavitation Phenomena in a Gerotor Pump Used for Automotive Applications", Energy Procedia, 2017, 126, Pages 1115-1122.

24. D. Buono, Schiano di Cola, F. D., A. Senatore, E. Frosina, Buccilli, G., Harrison, J., 2016, “Modelling approach on a Gerotor pump working in cavitation conditions" 70th Conference of the Italian Thermal Machines Engineering Association, ATI 2016, Energy Procedia, DOI: 10.1016/j.egypro.2016.11.089.

25. Altare G., Rundo M. "CFD Analysis of gerotor lubricating pumps at high speed: geometric features influencing the filling capability", Proceedings of the ASME/BATH 2015 Symposium on Fluid Power and 
Motion Control (FPMC), Oct. 12-14, 2015, Chicago, IL, USA. Paper no. FPMC2015-9539. DOI: 10.1115/FPMC2015-9539. Scopus: 2-s2.0-84964403756.

26. Rundo M. "Theoretical flow rate in crescent pumps", Simulation Modelling Practice and Theory 71: 1-14, 2017. DOI: 10.1016/j.simpat.2016.11.001.

27. Rundo M., Squarcini R., "Modelling and Simulation of Brake Booster Vacuum Pumps", SAE International Journal of Commercial Vehicles 2013, 6(1): 236-248, ISSN:1946-391X, DOI:10.4271/2013-01-9016

28. E. Frosina, A. Senatore, D. Buono, L Santato, 2013, Analysis and simulation of an oil lubrication pump for the internal combustion engine, ASME International Mechanical Engineering Congress and Exposition, 2013, Proceedings IMECE Volume $7 \mathrm{~B}$.

29. A. Senatore, D. Buono, E. Frosina, A. De Vizio, P. Gaudino, A. Iorio, "A Simulated Analysis of the Lubrication Circuit of an In-Line Twin Automotive Engine" SAE 2014 World Congress and Exhibition; Detroit, MI, USA, ISSN 0148-7191 doi: 10.4271/2014-01-1081, Scopus Code= 2-s2.0-84899537842

30. Rundo M. "Piloted Displacement Controls for ICE Lubricating Vane Pumps", SAE Int. Journal of Fuels and Lubricants , 2010, 2(2): 176-184, ISSN 1946-3952, DOI: 10.4271/2009-01- 2758.

31. Casoli, P., Pastori, M., Scolari, F., Rundo, M. "A vibration signal-based method for fault identification and classification in hydraulic axial piston pumps" Energies, 2019, 12 (5), art. no. 953, DOI: 10.3390/en12050953

32. Casoli, P., Campanini, F., Bedotti, A., Pastori, M., Lettini, A., Overall Efficiency Evaluation of a Hydraulic Pump with External Drainage Through Temperature Measurements, 2018, Journal of Dynamic Systems, Measurement and Control, Transactions of the ASME, 140 (8), art. no. 081005, DOI: 10.1115/1.4039084

33. Finesso R., Rundo M. "Numerical and experimental investigation on a conical poppet relief valve with flow force compensation", Int. Journal of Fluid Power 18(2): 111-122, 2017, ISSN: 1439-9776. DOI: 10.1080/14399776.2017.1296740.

34. Barbara Zardin, Massimo Borghi, Giovanni Cillo, Carlo Alberto Rinaldini, Enrico Mattarelli, Design Of TwoStage On/Off Cartridge Valves For Mobile Applications, Energy Procedia, Volume 126, 2017, Pages 1123-1130, ISSN 1876-6102, https://doi.org/10.1016/j.egypro.2017.08.275.

35. E. Frosina, D. Buono, A. Senatore, I. J. Costin. A Simulation Methodology Applied on Hydraulic Valves for High Fluxes. International Review on Modelling and Simulations 2016, 9(3):217, doi: 10.15866/iremos.v9i3.9612.

36. Finzel, M.; Helduser, S.; Jang D.; Electro-Hydraulic Dual-Circuit System to Improve the Energy Efficiency of Mobile Machines. In Proceedings of the 7th International Fluid Power Conference (IFK), Aachen, Germany, 2010.

37. Hansen, A.; Pedersen, H.; T. Andersen, and L. Wachmann, L.; Investigation of energy saving separate meterin separate meter-out control strategies, In the 12th Scandinavian International Conference on Fluid Power, SICFP'11, Tampere, Finland, 2011.

38. Hippalgaonkar, R.; Ivantysynova, M.; A Series-Parallel hydraulic hybrid mini-excavator with displacement controlled actuators. The 13th Scandinavian International Conference on Fluid Power, SICFP2013, June 3-5, 2013, Linköping, Sweden.

39. Lin, T.; Wang, Q.; Hu, B.; Gong, W. Research on the energy regeneration systems for hybrid hydraulic excavators. Autom. Constr. 2010, 19, 1016-1026..

40. Gong, J.; He, Q.; Zhang, D.; Zhang, Y.; Liu, X.; Zhao, Y.; Liu, C. Power system control strategy for hybrid excavator based on equivalent fuel consumption. In Proceedings of the 2012 IEEE International Conference on Mechatronics and Automation, Chengdu, China, 5-8 August 2012.

41. Li, W.; Wu, B.; Cao, B. Control strategy of a novel energy recovery system for parallel hybrid hydraulic excavator. Adv. Mech. Eng. 2015, 7, 1-9.

42. Schneider, K. Liebherr pactronic-hybrid power booster. In Proceedings of the 8th International Fluid Power Conference (IFK), Dresden, Germany, 2012.

43. Casoli, P.; Gambarotta, A.; Pompini, N.; Riccò, L. Hybridization methodology based on DP algorithm for hydraulic mobile machinery-Application to a middle size excavator. Autom. Constr. 2016, 61, 42-57.

44. Padovani, D., Rundo, M., Altare, G. The Working Hydraulics of Valve-Controlled Mobile Machines: Classification and Review. J. Dyn. Sys., Meas. Control 2020, 142(7), 070801. DOI:10.1115/1.4046334.

45. J. Rosero, J. Ortega, E. Aldabas and L. Romeral. Moving Towards a more Electric Aircraft. IEEE A\&E System Magazine, 2007 pp. 3-9, March. DOI: 10.1109/MAES.2007.340500 
46. M. Schneider, O. Koch, and J. Weber. Green Wheel Loader - improving fuel economy through energy efficient drive and control concepts. 10th Int. Fluid Power Conf., Dresden, 2016.

47. S. Smith, J. Irving and J. Irving. Electro Hydrostatic Actuators for Control of Undersea Vehicles. Joint Undersea Warfare Technology Fall Conference, 2006 Groton, Connecticut.

48. Schmidt, L., Ketelsen, S., Brask, M.H., Mortensen, K.A. A Class of Energy Efficient Self-Contained ElectroHydraulic Drives with Self-Locking Capability. Energies 2019, 12, 1866, doi:10.3390/en12101866.

49. Ketelsen S., Padovani D., Andersen T.O., Ebbesen M.K., Schmidt L. Classification and Review of PumpControlled Differential Cylinder Drives. Energies 2019, 12. 1293. DOI:10.3390/en12071293

50. P. Casoli, A. Gambarotta, N. Pompini, L. Riccò. Development and application of co-simulation and controloriented modeling in the improvement of performance and energy saving of mobile machinery. Energy Procedia, 2014, Volume 45, Pages 849-858. Elsevier. doi:10.1016/j.egypro.2014.01.090.

51. P. Casoli, A. Anthony, L. Riccò. Modeling of an Excavator System - Load sensing flow sharing valve model. SAE 2012 Commercial Vehicle Engineering Congress, Rosemont, Illinois, USA, 13-14 September 2012. doi:10.4271/2012-01-2042.

52. Bedotti, A., Campanini, F., Pastori, M., Riccò, L., Casoli, P. Energy saving solutions for a hydraulic excavator. Energy Procedia 2017, 126, pp. 1099-1106 DOI: 10.1016/j.egypro.2017.08.255

53. Paolo Casoli, Luca Riccò, Federico Campanini, Andrea Bedotti. Hydraulic Hybrid Excavator-Mathematical Model Validation and Energy Analysis, Energies, 2016, 9, 1002; doi:10.3390/en9121002

54. P. Casoli, A. Anthony, M. Rigosi. Modeling of an Excavator System - Semi empirical hydraulic pump model" SAE - International Journal of Commercial Vehicles, 2011 vol. 4, Issue 1, pp. 242- 255. ISSN: 1946-391X. doi:10.4271/2011-01-2278.

55. P. Casoli, N. Pompini, L. Riccò. Simulation of an Excavator Hydraulic System Using Nonlinear Mathematical Models. Strojniški Vestnik - Journal of Mechanical Engineering 2015, 61, 10, 583-593. DOI:10.5545/svjme.2015.2570

56. P. Casoli, L. Riccò, F. Campanini, A. Lettini, C. Dolcin. Mathematical model of an hydraulic excavator for fuel consumption predictions" Proceedings of the ASME/BATH Symposium on Fluid Power \& Motion Control FPMC2015 October 12-14, 2015, Chicago, Illinois, United States ISBN: 978-0-7918-5723-6. Paper No. FPMC2015-9566, pp. V001T01A035; 10 pages. doi:10.1115/FPMC2015-9566

57. Earth-Moving Machinery - Fuel Consumption on Hydraulic Excavator-Test Procedure; JCMAS H020:2007; Japan Construction Machinery and Construction Association for Hydraulic Excavators: Tokyo, Japan, 2007. 